\title{
SOCIAL AND SAMPLE SURVEYS FOR PLANNING AND ECONOMIC POLICIES
}

$\mathrm{P}$ OLITICAL and Economic Planning is at present engaged on a major study into the whole field of the relations between government and industry, and the means by which the government gets its policy carried out. From this point of view of the ways of translating planning into practice, a recent broadsheet (No. 310) discussed the approach to planning and planning techniques so far as they are indicated in three recent books : Prof. W. Arthur Lewis's "Principles of Economic Planning"; Dr. T. Balogh's "The Dollar Crisis, Causes and Cure"; and the United Nations experts' report on 'National and International Measures for Full Employment". The three books between them cover the greater part of the possible methods of translating planning principles into practice and indicate the current state of thought on the relation between the theory and practice of planning.

The first two were prepared for the Fabian Society ; but whereas Dr. Balogh argues for selective controls which permit incentive to be given to progressive and efficient managements, Prof. Lewis regards planning through the market as the more flexible method. Only Prof. Lewis deals with the important point of mobility of reserves and labour in a full-employment policy, and his contribution is not sufficiently precise to be useful. All three books insist that the economy of a country cannot be planned in isolation from the rest of the world. The broadsheet, however, gives a comparative rather than a positive appraisal of the three approaches, reserving judgment until the factor involved in the psychological problem as well as that of organisation can be more accurately assessed.

Meanwhile, two further broadsheets dealing with one particular technique-the sample survey-have appeared (Nos. 313 and 314). The first of these examines the techniques used in such surveys to obtain facts about human activitios and describes the recent work of the Government Social Survey and the use of sample surveys in market research. It emphasizes that the technique of sample surveys is not one for amateurs or untrained persons, and at present not all those who conduct sample surveys have the necessary knowledge and skill. The appropriate techniques vary widely, like the needs of users of sample surveys; and the limitations of the present methods can only be fully appreciated if the particular needs are considered separately.

In general, users must consider such questions as what degree of accuracy is required; whether detailed information and a correspondingly detailed interview are wanted; the extent to which informants are likely to be interested in the purpose of the interview, and the level of public co-operation needed to ensure successful interviews; the form of the question, record or observation that is appropriate to the problem in hand. When these questions have been answered, it can be decided what degree of skill will be required in the investigator, and whether a solution of the problem will involve detailed analysis and a high level of statistical competence in handling the results obtained. That is to say, what issues from a survey depends upon what is put into it; and, if the technique of sample surveys is not to be discredited, it is important, as the broadsheet rightly urges, that there should be a wider public understanding of the technical requirements for efficient surveys.
On the Government Social Survey, Political and Economic Planning concludes that this has proved an administrative tool of permanent value which provides a reliable and economical means of collecting facts needed both for policy-making and for assessing the effects of changes in policy on sections of the population. Nevertheless, it is doubtful whether government work benefits as much as it might from the existence of the Social Survey. In many branches of government activity decisions are either being made without previous assessment of the social facts, or withheld or delayed because it is believed errone. ously that such facts are impossible to get. Decisions of the Ministry of Food are cited to illustrate this point, and it is also suggested that the nationalized industries should utilize the Social Survey.

The second broadsheet continues the review by discussing the use, and the criticisms of, publicopinion polls ; the problems of readership surveys; how the British Broadcasting Corporation discovers the sizes and preferences of its audiences; and the uses of sample surveys in making special studies, particularly in the medical sphere, without the aid of permanent survey staffs. For success such surveys depend on the use of the services of workers skilled in other fields, and they are chiefly of value in enabling a wide field to be surveyed and profitable lines of inquiry to be determined for closer study. The broadsheet is careful not to exaggerate the importance of sampling methods and points out that too much importance can be attached to them. Some surveys may yield results directly useful in determ: ining policy; others may only indicate the need for wide or more detailed research. The sample survey is no more than a rapid way of getting at the salient facts of a situation, and its advantage lies in the fact that it makes judgment freer by enabling it to concentrate immediately on the important issues.

Within these limits, Political and Economic Planning holds that the techniques of sample surveys are by no means fully developed, nor are the possibilities of present methods fully exploited. It is important that a professional spirit should develop among practitioners, and here the Market Research Society and the European Society for Opinion Surveys and Market Research could help. It is also suggested that the Government might provide the Social Survey with facilities enabling it to carry out the functions of a research organisation in the field of sample surveys. Survey reports also should be more widely available, and the possibilities offered by sampling methods should be made better known within the Civil Service. Warning is given against the use of departmental machinery when objective social results are needed. It is also suggested that a wider use of market research in industry at home might do much towards reducing costs, and that in overseas marketing full use of the facilities offered by the British Export Trade Research Organisation and like bodies would help to eliminate the "hit and miss" methods which are all too characteristic of Britain's present overseas trading. Intelligently conducted public-opinion surveys could also show one half of the world what the other half thinks-and why-and could thus zdd something of real value to the general discussion of social and political issues which is a part of democratic organisation. 